\title{
A IMPLANTAÇÃO E AVALIAÇÃO DO PROJETO AEROPOLVO NO ATENDIMENTO NEONATAL DO SERVIÇO AEROMÉDICO NO OESTE DO PARANÁ
}

\author{
Vanessa COLDEBELLA'; Liandra Kasparowiz GRANDO²
}

\section{RESUMO}

O projeto "Octo Project" ("Projeto Polvo") foi idealizado na Dinamarca em 2013 com a intenção de minimizar o impacto da internação em Unidades de Terapias Intensivas Neonatais (UTINs) acalmando e protegendo os recém nascidos (RNs). No intuito de trazer essa humanização e maior conforto no atendimento aos RNs realizado pela equipe do Serviço Aeromédico no Oeste do Paraná Base Cascavel, juntamente com a aquisição do abafador auricular neonatal, implantou-se o Projeto Aeropolvo. Sendo o objetivo desse estudo a apresentação e avaliação desse projeto. Trata-se de um estudo transversal de abordagem descritiva retrospectiva e a amostra foram os RNs prematuros atendidos entre setembro de 2017 a abril de 2018 totalizando $20 \mathrm{RNs}$, dos quais foram coletados sinais vitais (Saturação OxigênioSPO2, Frequência Cardíaca- FC e Temperatura- T) anotados em uma planilha. Com base nos dados expostos não se teve registro de nenhuma piora do quadro geral dos RNs transportados. Na maioria dos RNs atendidos foi verificado melhora do estado geral identificado pela elevação da SPO2 e diminuição da FC, bem como nenhum RN transportado apresentou faces de choro ou movimento corporal de dor o que nos confirma o conforto. Pelo resultado positivo da pesquisa acredita-se ter embasamento não só para a continuidade do projeto como sua ampliação a todos os RNs, estendendo esse cuidado humanizado carregado de amor e proteção.

PALAVRAS-CHAVE: resgate aéreo, neonatologia, humanização da assistência

\section{INTRODUÇÃO}

O Projeto Octo - Polvo Terapêutico foi criado na Dinamarca em 2013 para ajudar bebês recém-nascidos prematuramente a se sentirem mais seguros e confortáveis nas incubadoras no ambiente hospitalar, dando aos RNs um polvinho de crochê em fios 100\% algodão com 8 tentáculos de $22 \mathrm{~cm}$ de comprimento, segundo o estudo, os tentáculos do polvo assemelham-se ao cordão umbilical e reproduzem, de certa forma, o ambiente no interior do útero da mãe trazendo segurança e ainda evitando acidentes e choques nas paredes da incubadora (THE DANISH OCTO PROJECT, 2017).

No intuito de trazer essa humanização e maior conforto no atendimento aos recém-nascidos (RNs) realizados pela equipe do Serviço Aeromédico no Oeste do

1 Enfermeira especialista em Medicina Aeroespacial e Transporte Aeromédico /Enfermeira assistencial do serviço aeromédico base Cascavel/PR. vanessacolde@gmail.com

2Enfermeira especialista em Medicina Aeroespacial e Transporte Aeromédico /Enfermeira assistencial do serviço aeromédico base Cascavel/PR. liandrakg@gmail.com 


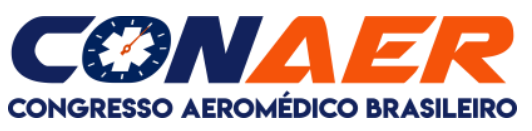

Paraná Base Cascavel, juntamente com a aquisição do abafador auricular neonatal, implantou-se o Projeto Aeropolvo, adaptando uma iniciativa a princípio desenvolvida somente em UTIs para a realidade do Aeromédico.

Assim, os objetivos propostos para o desenvolvimento do projeto Aeropolvo no serviço foram: inicialmente implantar o projeto polvo aos RNs prematuros (até 36 semanas); promover conforto e diminuir o stress dos RNs evitando complicações como a perda de peso e alterações hemodinâmicas; amenizar os efeitos do stress de voo (turbulência, ruídos, vibrações) nos RNs transportados; evitar que os bebês puxem dispositivos instalados como a sonda e tubos orotraqueais; mensurar através de planilha os sinais vitais dos RNs (na origem e durante voo) atendidos no projeto Aeropolvo no intuito de identificar o benefício (ou não) do objeto.

\section{METODOLOGIA}

Constitui-se um estudo transversal de abordagem descritiva retrospectiva, os dados foram obtidos por meio das planilhas preenchidas nos transporte neonatais de prematuros realizados pelo Serviço de transporte aeromédico base de Cascavel/PR. Fizeram parte da população de estudo os RNs prematuros atendidos entre setembro de 2017 a abril de 2018 totalizando 20 RNs.

\section{RESULTADOS E DISCUSSÃO}

Em 21/08/2017 após as devidas aprovações dos órgãos envolvidos no Serviço Aeromédico Base Cascavel (SESA PR e CONSAMU) e grupo de voluntárias consolidado para a confecção contínua dos polvos de crochê, foi realizado uma reunião com os enfermeiros da base dando início a implantação do projeto com apresentação da planilha a ser preenchida. A planilha foi elaborada com cabeçalho constando data, identificação do Recém nascido $(R N)$, sexo, idade gestacional, Apgar, suporte ventilatório, uso de sedação e droga vasoativa; abaixo uma tabela para anotação de Saturação Oxigênio, Frequência Cardíaca e Temperatura, dados a serem coletados na origem, durante o transporte aéreo (a cada 15 minutos) para se obter um comparativo do estado do RN. Lembrando que para o atendimento dos RNs contamos com o dispositivo de transporte Baby Pod (cápsula acolchoada com tampa transparente) aquecido por colchões térmicos, envolvemos os RNs em 


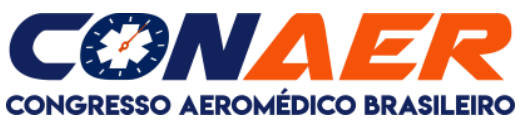

cueiros e cobertores (conforme necessidade) e utilizamos um abafador auricular neonatal que proporciona a redução de ruído em até $30 \mathrm{~dB}$. Possui-se no serviço um ventilador que cicla desde RNs prematuros à adultos, bem como aparelho multiparâmetros para monitorização contínua do RN e o termômetro digital de testa.

Do dia 07/09/2017 até o dia 07/04/2018 foram realizados 20 transportes com RNs prematuros de até 36 semanas e esse se constituiu o nosso coorte para estudo.

Nos transportes realizados mostrou a prevalência do gênero masculino 15 em relação ao feminino 5. De acordo com a idade gestacional segundo a Organização Mundial da Saúde e estudos de Almeida et al. (2013), tivemos 17 RNs classificados como prematuros moderados (32 a 36 semanas), 2 com prematuridade acentuada (28 e 31 semanas) e 1 com prematuridade extrema (inferior a 28 semanas). Em relação ao suporte ventilatório dos $\mathrm{RN}$ transportados, 12 foram removidos em campânula, 5 em ventilação mecânica assistida controlada, e 3 com suporte de CPAP. Quanto a medicação os 5 intubados receberam sedação e desses 3 também faziam uso de drogas vasoativas. A coleta dos sinais vitais (SSVV) para avaliação foram Saturação Oxigênio (SPO2), Frequência Cardíaca (FC) e Temperatura (T).

Em relação a SPO2 foi observado que 35\% dos RNs mantiveram em voo a porcentagem entre $93 \%$ e $99 \%$ encontrada na origem, e que 65\% apresentou melhora do parâmetro durante o transporte em relação à origem com porcentagens de até $84 \%$ encontradas na origem para valores de $95 \%$ a $98 \%$ no voo.

No que se refere a FC observou-se que 35\% dos RNs mantiveram os valores estáveis tanto na origem quanto durante o transporte, 5\% (1 RN) apresentou aumento do valor mas ainda se mantendo entre os valores considerados normais pelo Ministério da Saúde citado por Freitas et al. (2011) onde RN pré termos podem apresentar FC de 100 a 180bpm, e 60\% dos atendidos apresentaram diminuição dos valores durante o voo em relação a origem.

Em relação a temperatura $90 \%$ dos $\mathrm{RN}$ avaliados mantiveram temperatura entre $36,1^{\circ} \mathrm{C}$ e $37^{\circ} \mathrm{C}$ tanto na origem como durante o voo, $01 \mathrm{RN}$ apresentou hipotermia moderada na origem $\left(35,6^{\circ} \mathrm{C}\right)$ sendo que durante o transporte apresentou estabilização com $36,7^{\circ} \mathrm{C}$ e $01 \mathrm{RN}$ apresentava-se hipertérmico $\left(38^{\circ} \mathrm{C}\right)$ na origem e que também durante o voo estabilizou em $37^{\circ} \mathrm{C}$.

De acordo com o Departamento de Neonatologia da Sociedade Brasileira de Pediatria uma série de parâmetros físicos e comportamentais se modifica no recémnascido diante de um estímulo doloroso, desde a freqüência cardíaca e respiratória, 


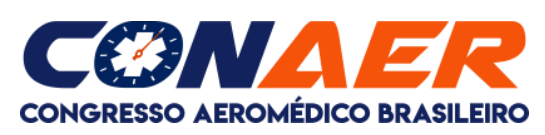

a saturação de oxigênio, até o movimento corporal, a mímica facial e o choro, entre outros. Dentre os parâmetros fisiológicos de dor, os mais utilizados para a avaliação clínica são a freqüência cardíaca, a freqüência respiratória, a saturação de oxigênio onde infere-se que esses parâmetros seja uma forma de comunicação entre o RN e seu cuidador (GUINSBURG; CUENCA, 2010).

Com base nos estudos expostos e considerando a leitura dos valores dos SSVV obtidos dos RNs na origem e durante o transporte, não foram encontrados registros de piora do quadro geral dos RNs transportados. Na maioria dos RNs atendidos foi verificado melhora do estado geral identificado pela elevação da Saturação de Oxigênio em $65 \%$ e pela diminuição da Frequência cardíaca em $60 \%$ o que nos confirma o conforto e a estabilidade. Observou-se que 35\% mantiveram os mesmos valores de vitais estáveis encontrados na origem o que para o estudo também pode ser apontado como benéfico e positivo já que o RN no transporte aeromédico é exposto a vários fatores estressantes (ruídos, vibrações e turbulência) e que assim, ficou demonstrado que, com os dispositivos implementados (polvo e abafador) conseguimos manter o ambiente controlado da unidade hospitalar. $O$ dado temperatura além de nos apresentar que é possível manter níveis satisfatórios de calor para estabilização da temperatura no RN utilizando o dispositivo Baby pod com colchões térmicos, também teve o intuito de demonstrar que não interferiu no parâmetro frequência cardíaca, pois RNs superaquecidos/hipertérmicos apresentam aumento da frequência cardíaca e respiratória (ROLIM et al.,2010).

Assim, além dos dados vitais anotados em planilha, em reuniões da equipe foram discutidos os transportes já realizados sendo importante registrar que nenhum RN transportado apresentou faces de choro ou movimento corporal de dor o que corrobora juntamente com os SSVV o estado confortável que se apresentavam.

\section{CONSIDERAÇÕES FINAIS}

Levando-se em consideração o ambiente aeromédico com tantos estressores envolvidos, a pesquisa demonstrou resultados extremamentes positivos quanto ao bem estar dos RNs transportados e acima de tudo o não dolo do objeto Polvo Terapêutico aplicado. Acredita-se que com este estudo a equipe do Serviço Aeromédico base Cascavel/PR possui embasamento não só para dar continuidade ao projeto como amplia-lo a todos os RNs ( 0 a 28 dias) prematuros ou não, 
estendendo esse cuidado humanizado carregado de amor e proteção.

\section{REFERÊNCIAS}

1. ALMEIDA TSO et al. Investigação sobre os Fatores de Risco da Prematuridade: uma Revisão Sistemática. R bras ci Saúde. 2013; 17(3): 301-308.

2. FREITAS, Fernando et al. Rotinas em obstetrícia. 2011 6. ed. Porto Alegre: Artmed. P. 902. ISBN 978-85-3632433-3.

3. GUINSBURG, Ruth; CUENCA, Maria Carmenza. A Linguagem da Dor no Recémnascido. Documento Científico do Departamento de Neonatologia Sociedade Brasileira de Pediatria. Escola Paulista de Medicina da Universidade Federal de São Paulo. São Paulo, 2010.

4. ROLIM, Carneiro et al. Cuidado quanto à termorregulação do recém-nascido prematuro: o olhar da enfermeira. Revista da Rede de Enfermagem do Nordeste. v.11, n.2, p.44-52, 2010.

5.THE DANISH OCTO PROJECT. Disponível em: https://www.spruttegruppen.dk/danish-octo-project-english/>. Consultado em 07 de jul/2019. Um Polvo de Amor: saiba tudo sobre essa iniciativa. ONG Prematuridade.com. 